\title{
Seroconversion after hepatitis B vaccination in healthy young adults, and the effect of a booster dose
}

\author{
Jennifer Perera', Bernadene Perera ${ }^{2}$, and Siritilak Gamage ${ }^{3}$
}

(Index words: Anti-HBs titres, non-responders, hypo-responders)

\begin{abstract}
Objective Previous studies have shown that $5 \%$ to $15 \%$ of healthy people do not show a protective antibody response following hepatitis $B$ vaccination. The study was done to determine the protective efficacy of vaccination in healthy young adults 1 to 4 years after the three dose vaccination series and to study the effect of a booster dose on nonresponders and hypo-responders.

Design Prospective intervention study.

Setting From January to June 2000, Faculty of Medicine, University of Colombo.

Study group 258 volunteers from five batches of medical students vaccinated with three doses of the recombinant vaccine at 0,1 and 6 months.

Results $9.5 \%$ were non-responders. Duration of vaccination, sex and body mass index were not significantly associated with anti-HBs levels. $28.6 \%$ had potential risk factors for acquiring HBV infection. $86.3 \%$ of non-responders developed protective anti-HBs titres after a booster dose. The persistent non-responders did not have a chronic illness or past $\mathrm{HBV}$ infection.

Conclusions A substantial number do not seroconvert after hepatitis B vaccination. Testing of blood for anti-HBs one month after vaccination is recommended to recognise nonresponders as a booster dose will be beneficial in the majority of them.
\end{abstract}

\section{Introduction}

The discovery of the aetiologic agent of hepatitis B (HB) and the development of safe and effective vaccines is one of the remarkable achievements of the 20th century. HB is transmitted by percutaneous or permucosal exposure to infectious body fluids, by sexual contact with an infected person and perinatally from an infected mother to her infant. The consequences of acute hepatitis $B$ virus (HBV) infection are variable. Newborn babies are generally asymptomatic and the typical illness is seen in only 5 to $15 \%$ of children 1 to 5 years of age (1). Older children and adults are symptomatic in 33 to $50 \%$ of infections. Fulminant hepatitis occurs in 1 to $2 \%$ of people with acute disease, which has a case fatality rate of 63 to $93 \%$.

Chronic HBV infection is defined as the presence of $\mathrm{HBsAg}$ in serum for at least 6 months. The risk of developing chronic infection is highest for infants (about 90\%) infected in the perinatal period, compared to 6 to $10 \%$ of acutely infected adults (2). 15\% of adolescents and young adults with chronic HBV infection are at substantially increased risk of developing chronic liver disease, including cirrhosis of the liver and hepatocellular carcinoma.

In Sri Lanka epidemiological surveys of the community and in blood donors show that the prevalence of chronic HBV infection is low, ranging between 0.7 and $2.5 \%$ (3). A survey in 1996 showed a prevalence of $0.15 \%$ among all categories of health care workers (3/2000) and $0.5 \%$ in medical officers (1/206) (4). A study of 456 medical students before exposure to clinical work showed a prevalence of $0.44 \%$ (5).

Vaccination of individuals at risk of exposure to HBV has been the main method of controlling the morbidity and mortality associated with HBV. The recommended schedule of vaccination of healthy subjects consists of three doses at 0,1 and 6 months. The protective efficacy of HB vaccination is directly related to the development of anti-HBs antibodies. Those who develop anti-HBs titres of $>10 \mathrm{mIU} / \mathrm{ml}$ after a primary vaccination series are protected against clinical illness and chronic infection (6). Studies of the antibody response to currently licensed plasma derived hepatitis B vaccines and hepatitis B vaccines prepared by recombinant technology have shown that between 5 to $10 \%$ or more of healthy people do not show an anti-HBs antibody response to the surface antigen component (HbsAg) of these preparations (nonresponders), or respond poorly (hypo-responders) (7), conditions that are defined as showing less than $10 \mathrm{mIU} /$ $\mathrm{ml}$ and 10 to $100 \mathrm{mIU} / \mathrm{ml}$ of anti-HBs respectively against an international antibody standard. Non-responders remain susceptible to infection with $\mathrm{HBV}$.

The recommended series of three intramuscular doses of $\mathrm{HB}$ vaccine induces a protective antibody response in over $90 \%$ of healthy adults below 40 years of age. By the age of 60 years only $75 \%$ of people vaccinated develop protective levels of anti-HBs (8). Host factors such as smoking, obesity, immunosuppression, past HBV infection, of immune deficiency disorders and chronic illnesses adversely affect the antibody response.

\section{Methods}

Study group

The study was conducted at the Faculty of Medicine, Colombo from January to June 2000 . The study popu- 
lation comprised 258 medical students who had been vaccinated with three doses of the recombinant vaccine intramuscularly to the deltoid region at 0,1 and 6 months.

\section{Study design}

Blood samples from the study group were tested for anti-HBs titre using a quantitative enzyme linked immunosorbent assay (ELISA) by Abbot-Murex. Data on factors known to affect seroconversion were obtained using a self-administered questionnaire. The data included sex, age, body weight and height, duration after vaccination, presence of a chronic disease such as diabetes and other immune deficiency states.

The risk of infection with HBV was also assessed from a history of needle pricks, family or close contact with a chronic carrier of $\mathrm{HBV}$ and sexual contact.

In the second phase of the study, participants who did not have protective antibody levels (non-responders, anti-HBs less than $10 \mathrm{mIU} / \mathrm{ml}$ ) and hypo-responders (antiHBs less than $100 \mathrm{mIU} / \mathrm{ml}$ ) were given a booster dose of the vaccine and retested after one month for seroconversion or a rise in the anti-HBs antibody titre. Participants who did not seroconvert after this were investigated further by an interview to probe their past medical history and by testing for serological evidence (anti-HB core antibody) of past HBV infection.

\section{Results}

The participants were from 13 districts of the island, and the percentages were, Colombo 58.2, Gampaha 15.5, Kalutara 8.8, Kegalle 3.6, Matara 3.6, Galle 2.8, Kurunegala 2.4, Ratnapura 2.0, Hambantota 0.8, Puttalama 0.4, Nuwara Eliya 0.4 and Badulla 0.4 . The numbers of volunteers from the five batches of students and the duration after vaccination are shown in Table 1. 90.3\% (223/258) showed a protective antibody response (anti-HBs $\geq 10 \mathrm{mIU} / \mathrm{ml}$ ) following vaccination. $9.5 \%$ were non-responders. The majority (54\%) showed a good antibody response $(\geq 100 \mathrm{mIU} /$ $\mathrm{ml})$ against HBV infection. Table 2 shows the anti-HBs titres in relation to duration of vaccination. In our study there was no significant association between the anti-HBs titre and duration after vaccination which varied from 12 to 40 months. Sex and body mass index were not significantly associated with seroconversion. Type of vaccine, dose and route of vaccination were not significant variables.

In the study population 64 gave a history of accidental needle pricks, 2 had close contact with a chronic hepatitis B patient, and 8 have had homosexual or heterosexual intercourse. Hence $28.6 \%$ had a potential risk factor for acquiring $\mathrm{HBV}$ infection.

Among the 26 non-responders (anti-HBs $<10 \mathrm{mIU} /$ $\mathrm{ml}), 22$ volunteered for retesting after a booster dose of HB vaccine. Among the 103 hypo-responders 12 who had antiHBs titres of $10-100 \mathrm{mIU} / \mathrm{ml}$ were retested after a booster dose. All hypo-responders developed anti-HBs titres over $100 \mathrm{mIU} / \mathrm{ml}$. Among the 22 initial non-responders, 3 (13.6\%) continued to be negative for anti-HBs antibodies, but did not have any identifiable chronic illness and tested negative for anti-HB core ( $\mathrm{HBC}$ ) antibodies indicating absence of past HBV infection.

Table 1. Number of student volunteers from each batch and duration after vaccination

Batch

Number studied Duration after vaccination (months)

$\begin{array}{lll}1992 / 93 & 38 & 41 \\ 1993 / 94 & 68 & 28 \\ 1994 / 95 & 51 & 28 \\ 1995 / 96 & 49 & 12 \\ 1996 / 97 & 52 & 12\end{array}$

Total 258

Table 2. Anti-HBs antibody levels and duration after vaccination

Duration after the third dose (months)

$$
\begin{aligned}
& 40(n=38) \\
& 28(n=119) \\
& 12(n=101) \\
& \text { Total }(n=258)
\end{aligned}
$$

Number of non-
responders (\%)
$3(7.9)$
$11(9.2)$
$12(11.5)$
$26(9.5)$

Responders and anti-HBs titres in $\mathrm{mlU} / \mathrm{ml}$ $10-100(\%) \quad 100-1000(\%) \quad>1000(\%)$

$\begin{array}{rrr}9(23.7) & 23(60.5) & 3(7.9) \\ 51(42.8) & 53(44.6) & 4(3.4) \\ 43(42.5) & 41(41.0) & 5(5.0) \\ 103(36.3) & 117(48.7) & 13(5.4)\end{array}$




\section{Discussion}

The minimum protective level of anti-HBs following immunisation has been set in protective efficacy studies at $10 \mathrm{mIU} / \mathrm{ml}$. The titre required for protection against particular routes of infection and the size of the inoculum may vary. For example, a follow up study of vaccinated homosexual men reported an overall incidence of $\mathrm{HBV}$ infection of 2.9 per 100 person years, with nearly $75 \%$ occurring in people with an anti-HBs titre less $10 \mathrm{mIU} / \mathrm{ml}$ at the time of infection, and in only a few with anti-HBs titres over 50 $\mathrm{mIU} / \mathrm{ml}$ (10). A much lower asymptomatic HBV infection rate of 0.8 per 100 person years was observed after immunisation of health care workers in nephrology units who had antibody titres less than $50 \mathrm{mIU} / \mathrm{ml}$ (11).

Vaccine induced anti-HBs titres are highest one month after booster vaccination, but decline rapidly during the next 12 months and thereafter more slowly (6).

Providing booster vaccination to all vaccinated subjects at regular intervals without determination of anti-HBs is not supported by evidence $(15,16)$. Testing of the antibody level one month after the last dose of vaccination is recommended to identify non-responders and hyporesponders $(16,17)$. Numerous studies indicate that administration of four, five, six or more doses of the vaccine in non-responders or hypo-responders results in production of protectice levels of anti-HBs in about $50 \%(12,13,14,15)$. In our study a booster dose of the vaccine resulted in $86 \%$ of non-responders developing protective anti-HBs levels.

The European Consensus Group on hepatitis B immunisation recommends the following for health care workers and others at occupational risk who do not develop protective anti-HBs titres after the initial vaccination series (16): screen for markers of present or past $\mathrm{HBV}$ infection ( $\mathrm{HbsAg}$, anti-HBc); administer an additional booster dose of the vaccine, repeat anti-HBs measurement; consider passive immunisation with $\mathrm{HB}$ immunoglobulin following exposure.

The US Public Health Service Guidelines for the management of occupational exposures to $\mathrm{HBV}$ recommends that people who do not respond to the primary vaccine series be given a second 3-dose series as there is a 30 to $50 \%$ chance of responding to the latter (17).

\section{Acknowledgements}

We are grateful to the medical students who participated in the study, the University of Colombo for financial assistance, Drs Thushara Amarasinghe, Nishadi Ranasinghe, Chandrika Ponnamperuma, Anuja Ponnamperuma, Samanthi Jayamaha and Shivantha Fernandopulle for collection of blood, Ms Shirani Hendalage for secretarial assistance, and Mr P G Ratnasekera for laboratory assistance.

\section{References}

1. McMahon BJ, Alward WLM, Hall DB, Heyward WL, Bender TR, Francis DP et al. Acute hepatitis B virus infection: relation of age to clinical expression of disease and subsequent development of carrier state. Joumal of Infectious Disease, 1985; 151: 599-603.
2. Hyams KC. Risk of chronicity following acute hepatitis B virus infection, Clinical Infectious Diseases; 1995; 20: 992-1000.

3. de Silva HJ, Fonseka N, de Soysa NS, Premawardena AP. Seroepidemiology of hepatitis B and $C$ in Sri Lanka. In: Sarin SK, Hess G; eds. Transfusion associated hepatitis. New Delhi: CBS Publishers, 1998; 117-25.

4. de Zoysa NS, Jayaweera KKDG. Prevalence of HBV infection in health care workers and the general population in Sri Lanka. Sri Lanka Medical Association, $109^{\text {th }}$ Annual academic sessions, 1996.

5. Premawardhena AP, Premaratne R, Jayaweera G, Costa S, Chandrasena LG, de Silva HJ. Hepatitis $B$ and $C$ markers among new entrant medical students. Ceylon Medical Journal 1999; 44: 120-2.

6. Mahoney FJ. Update on diagnosis, management and prevention of hepatitis B virus infection. Clinical Microbiology Reviews 1999; 12: 351-66.

7. Zuckermann JN. Non-response to hepatitis $B$ vaccines and the kinetics of anti-HBs production. Journal of Medical Virology 1996; 50: 283-8.

8. Wood RC, MacDonald KL, White KE, Hedberg CW, Hanson M, Osterholm MT. Risk factors for lack of detectable antibody following hepatitis B vaccination of Minnesota health care workers. Journal of the American Medical Association 1993; 270: 2935-72.

9. Averhoff F, Mahoney FJ, Coleman PJ, Schatz G, Hurwitz E, Margolis HS. Risk factors and lack of response to hepatitis B vaccine: A randomised trial comparing the immunogenicity of recombinant hepatitis $B$ vaccines in an adult population. American Journal of Preventive Medicine 1998; 1: 73-7.

10. Hadler SC, Francis DP, Maynard SE, Thompson FN, Judson DF, Echenberg DG et al. Long term immunogenicity and efficacy of hepatitis B vaccination in homosexual men. New England Journal of Medicine 1986; 315: 209-14.

11. Courouce AM, Loplanche A, Benhamou E, Jungers P. Long term efficacy of hepatitis $B$ vaccination in healthy adults. New York: AR Liss, 1988.

12. Westmoreland D, Player V, Heap DC, Hammond A. Immunization against hepatitis B - what can we expect? Results of a survey of antibody response to immunizaton in persons 'at risk' of occupational exposure to hepatitis B. Epidemiology and Infection 1990; 104: 499-509.

13. Pasko MT, Beam TR Jr. Persistence of anti-HBs among health care personnel immunized with hepatitis B vaccine. American Journal of Public Health 1990; 80: 590-3.

14. Carven DE, Andeh ZL, Kunches LM, Yunis EJ, Dienstag JL, Werner BG et al. Non-responsiveness to hepatitis B vaccine in health care workers - results of revaccination and genetic typing. Annals of Internal Medicine 1986; 105: 356-60.

15. Fagan FA, Tolley P, Smith HM, Peters MP, Coleman J, Eliott $P$ et al. Hepatitis $B$ vaccine immunogenicity and follow up includ. ing two year booster doses in high risk health care personnel in a London teaching hospital. Journal of Medical Virology 1987; 21: 49-56.

16. European Consènsus Group on hepatitis B immunity. Are booster immunisations needed for lifelong hepatitis B immunity. Lancet 2000; 355: 561-5.

17. Updated US Public Health Service Guidelines for the management of occupational exposures to HBV, HCV and HIV and recommendations for post-exposure prophylaxis. Morbidity and Mortality Weekly Report 2001; 50: 15. 